\title{
Meckel's Enterolith Causing Small Bowel Obstruction: A Useful Solution to a Unique Problem
}

\author{
Gabriel De la Cruz Ku ${ }^{1}$, Erek Nelson ${ }^{1}$, Rolando Calderon ${ }^{1}$, Pouya Hemmati ${ }^{1}$, Brian Kim ${ }^{2}$ \\ 1. General Surgery, Mayo Clinic, Rochester, USA 2. Trauma and Acute Care Surgery, Mayo Clinic, Rochester, USA
}

Corresponding author: Brian Kim, kim.brian@mayo.edu

\begin{abstract}
Meckel's diverticulum (MD) is the most common congenital anomaly of the gastrointestinal tract. Its course is usually benign but may also result in complications requiring surgical intervention. A diverticulum may also permit the removal of intraluminal objects without bowel resection and anastomosis.
\end{abstract}

A woman in her 50s was found to have a mechanical small bowel obstruction secondary to an intraluminal mass within the terminal ileum. On exploration, an MD was encountered proximal to the mass. A diverticulectomy was performed after maneuvering the enterolith into the diverticulum.

Meckel's diverticulum with an associated enterolith is a rare cause of small bowel obstruction. Historic imaging may show long-standing stones in the bowel lumen and provide a diagnostic clue. Diverticulectomy may be performed to reduce the risks of small bowel resection and anastomosis. This technique can be used for other intraluminal objects requiring removal in the presence of an MD.

Review began 05/24/2021 Review ended 06/15/2021 Published 06/26/2021

(๑) Copyright 2021 De la Cruz Ku et al. This is an open access article distributed under the terms of the Creative Commons Attribution License CC-BY 4.0., which permits unrestricted use, distribution, and reproduction in any medium, provided the original author and source are credited.
Categories: General Surgery

Keywords: meckel's diverticulum, gastrointestinal obstruction, surgery general, surgical acute abdomen, diagnosis

\section{Introduction}

Meckel's diverticulum (MD) is caused by the incomplete obliteration of the vitelline duct during the seventh to eighth week of gestation [1]. It is present in approximately two percent of the population. Most MD are asymptomatic and, therefore, undiagnosed. A minority of those with MD will develop complications within their lifetimes. Diagnosis can be made by radiography, ultrasound, CT scan, or Technetium-99m pertechnetate. However, diagnosis is more challenging in adults compared to pediatric patients due to lower sensitivity and specificity [2]. An acute abdomen can be the initial presentation secondary to inflammation or bleeding. Less common presentations include herniation, malignancy, or obstruction. We present a case report and literature review of a small bowel obstruction caused by an enterolith formed within an MD. Although the presenting pathology is rare, benign intraluminal masses and MD are both more common. This case report demonstrates the technique of using an MD to extract an intraluminal mass.

\section{Case Presentation}

The patient is a woman in her 50s who presented to the emergency department (ED) with a two-day history of colicky abdominal pain in the mid-epigastrium and right lower quadrant associated with nausea, emesis, distention, and obstipation. She had a past medical history of hypertension and major depressive disorder treated with losartan and citalopram, respectively; and regarding her surgical history, she did not have any prior abdominal operation. She did not have symptoms or a history of biliary pathology.

On physical examination, her abdomen was distended and tympanitic, but nontender. Laboratory analysis revealed a normal white blood cell count and hemoglobin. Serum electrolytes were indicative of mild volume depletion.

She subsequently underwent a CT scan of the abdomen and pelvis which showed a distal small bowel obstruction with a transition point at a $2.9 \mathrm{~cm}$ round intraluminal structure with central calcification (Figure $1 B$ ). There was no evidence of small bowel ischemia or perforation. The patient did not have radiopaque cholelithiasis or imaging findings of cholecystoenteric fistula (Figure $1 A, B)$. Upon review of prior imaging, screening CT colonography from six years prior for cancer screening purposes showed a similar, but smaller intraluminal structure associated with the terminal ileum (Figure 1A). 


\section{Cureus}
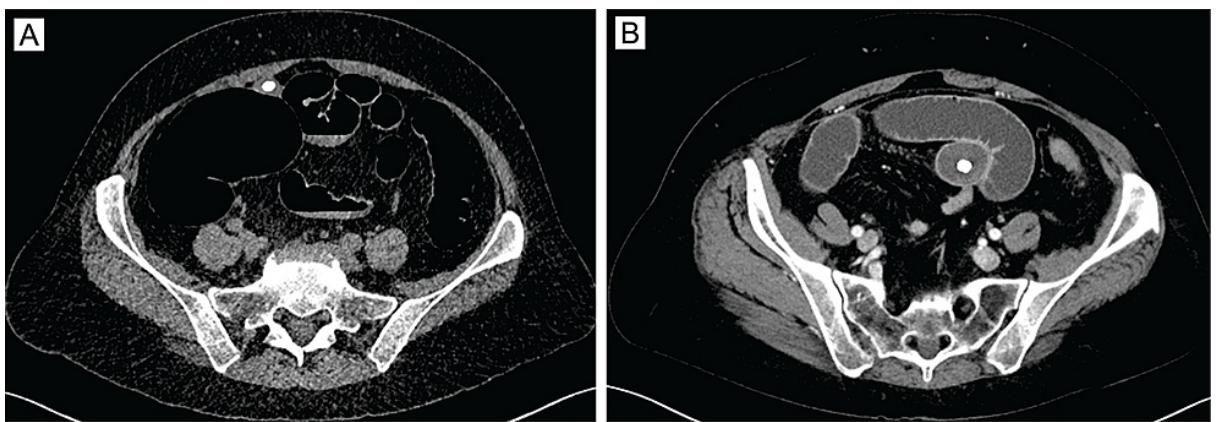

\section{FIGURE 1: CT showing with Meckel's enterolith.}

(A) Historic imaging: radiopaque intraluminal mass was seen near the terminal ileum on a screening CT colonography performed six years prior to presentation. This mass was smaller than the mass that was removed. The lower-density periphery had grown in diameter, but the radiopaque core was identical in appearance. (B) Preoperative imaging: CT scan with IV contrast showing an obstructive mass with a calcified core in the terminal ileum. Small bowel is decompressed distal to the obstruction and dilated proximal to it.

The differential diagnosis included teratoma or other benign or malignant mass, ingested foreign body, and gallstone ileus. While most surgeons hearing the history would suspect gallstone ileus, especially in patients with known biliary pathology, lack of visible cholecystoenteric fistula or inflammatory changes in the right upper quadrant precluded this diagnosis. The patient was a reliable historian and denied a history of unusual foreign body ingestion. While the imaging phenotype of a central calcification and concentric radiolucent material was reminiscent of a mature teratoma, this pathology arising in the small bowel of a middle-aged patient would be very unusual. Nevertheless, the mass had been present for at least six years and appeared to be enlarging. Therefore, an unknown malignancy was atop our differential diagnosis upon proceeding to the operating room.

After nasogastric decompression, she was taken to the operating room for exploratory laparotomy via a limited periumbilical midline incision. Fifty centimeters proximal to the ileocecal valve, a broad-based MD seven centimeters in length was identified. Twenty centimeters distal to the MD, a mobile, intraluminal, obstructing enterolith was found. The stone was milked proximally into the lumen of the MD and it matched the diameter of the diverticulum (Figure 2A-D). A stapled, transverse diverticulectomy was performed with the stone within the diverticulum. 


\section{Cureus}
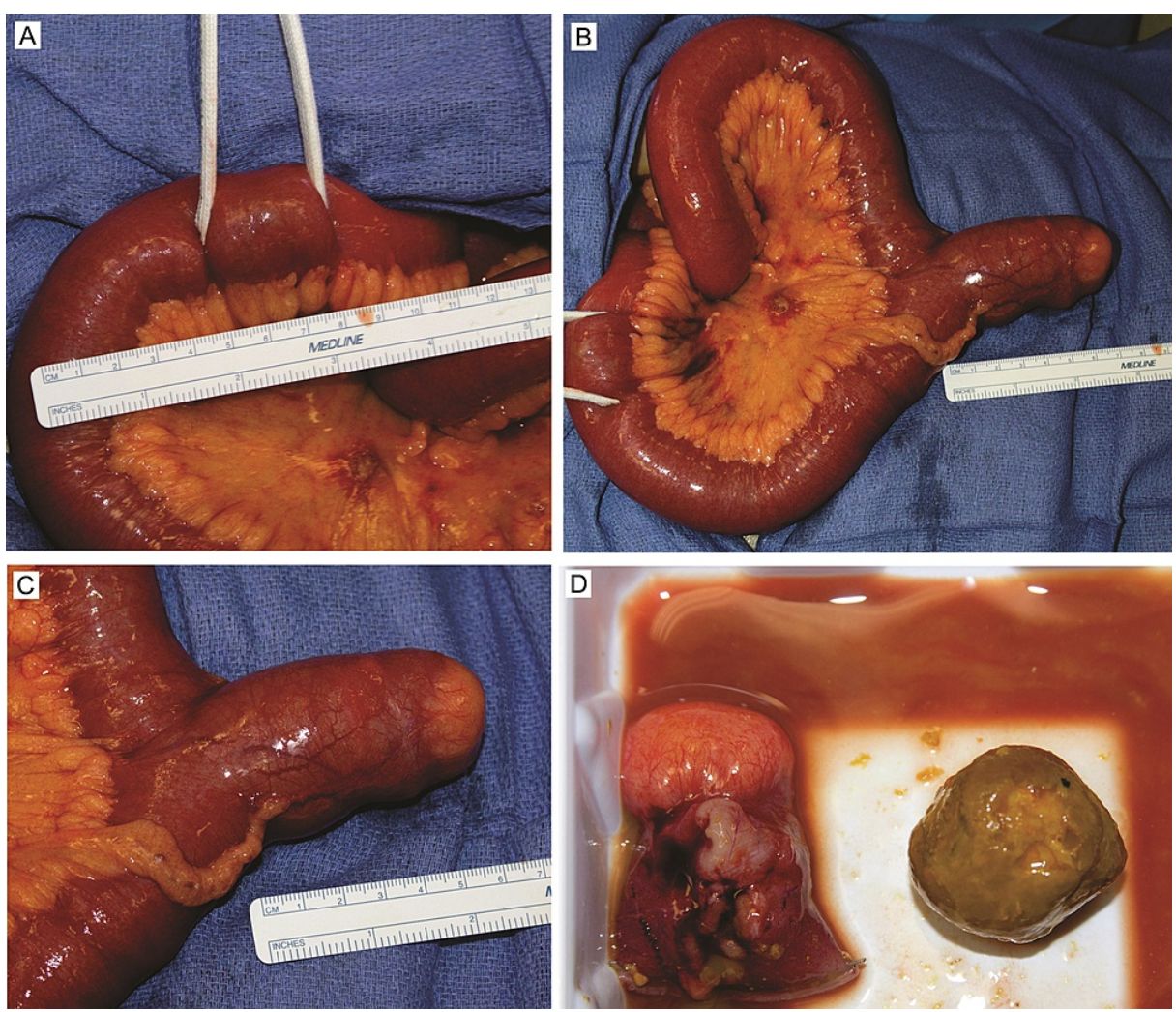

\section{FIGURE 2: Intraoperative findings.}

(A) A three-centimeter, mobile, intraluminal, obstructive mass was discovered at the transition point from dilated to the compressed small bowel. (B and C) Proximal to this, a broad-based MD was identified that was seven centimeters in length. (D) The mass fit within the diverticulum and was confirmed to be an enterolith after diverticulectomy.

MD, Meckel's diverticulum

Postoperatively, the patient progressed without complication and was discharged on postoperative day five after the return of bowel function. Final pathology confirmed a benign MD without ectopic mucosa. The patient is currently alive and well and, as recurrence is unlikely status post diverticulectomy, she has been surgically dismissed.

\section{Discussion}

Meckel's diverticulum is present in approximately two percent of the general population and is the most prevalent congenital abnormality of the gastrointestinal tract [3-4]. Only 16\% of patients with MD develop symptoms. Symptomatic MD is associated with age younger than 50 years, male sex, length greater than two centimeters, and presence of ectopic tissue such as gastric mucosa [5]. While the most common manifestation in children is hematochezia, obstructive symptoms are more common in adults [6-7]. Specifically, 36.5\% of adults with symptomatic MD present with small bowel obstruction secondary to fixation of the free tip of the diverticulum to the anterior abdominal wall, $13.5 \%$ with intussusception, $12.5 \%$ with diverticulitis, $11.3 \%$ with hemorrhage, $7.3 \%$ with perforation, and $3.2 \%$ with malignancy [8].

Obstruction secondary to MD-associated enterolith is rare, and the preoperative diagnosis is challenging. Moreover, although laparoscopic MD resection is common, there are no reports of laparoscopic diverticulectomy with the removal of an obstructing enterolith [9-10].

After a systematic search of Pubmed, Embase, Google Scholar and Lilacs, we found 30 cases of MD enteroliths causing small bowel obstruction from 1959 to 2020 (Table 1) [11-39]. The median age at presentation was 58 years (interquartile range, IQR $42-72$ years), with $73 \%$ of cases in males. Sixty-seven percent of cases were diagnosed with pre-operative imaging, although only $48 \%$ of enteroliths were radiopaque. Multiple stones were found in $23.5 \%$ of the cases. The average stone size was $3.6 \mathrm{~cm}$ (standard deviation, $\mathrm{SD} \pm 1.03 \mathrm{~cm}$ ), but ranged from 2.5 to $6 \mathrm{~cm}$. Enteroliths were found more frequently in the terminal ileum (58\%), while 38\% remained within the MD. 


\begin{tabular}{|c|c|c|c|c|c|c|c|c|c|}
\hline No & Author & Year & Country & Age & Sex & Diagnosis & Imaging features & Size & Location of enterolith \\
\hline 1 & Field et al. [11] & 1959 & USA & 52 & M & Surgical & Radiolucent & ND & SB \\
\hline 2 & Danzis et al. [12] & 1950 & USA & ND & ND & ND & ND & ND & ND \\
\hline 3 & Bergland et al. [13] & 1963 & USA & 73 & $F$ & Surgical & Radiolucent & $3 \mathrm{~cm}$ & SB \\
\hline 4 & Caridis et al. [14] & 1965 & France & ND & ND & ND & ND & ND & ND \\
\hline 5 & Sbriccoli [15] & 1969 & Italy & ND & ND & ND & ND & ND & ND \\
\hline 6 & Grosdidier et al. [16] & 1972 & France & ND & ND & ND & ND & ND & ND \\
\hline 7 & Benhamou [17] & 1979 & France & ND & ND & ND & ND & ND & ND \\
\hline 8 & Grant [18] & 1981 & Australia & 65 & $\mathrm{M}$ & Surgical & Radiolucent & ND & MD \\
\hline 9 & Lopez and Welch [19] & 1991 & USA & 85 & $M$ & Surgical & Radiopaque & $3 \mathrm{~cm}$ & MD \\
\hline 10 & Rudge [20] & 1992 & USA & 78 & $\mathrm{M}$ & Surgical & Radiolucent & $5 \mathrm{~cm}$ & SB \\
\hline 11 & McCallion et al. [21] & 1992 & Ireland & 37 & $\mathrm{~F}$ & Surgical & Radiolucent & ND & SB \\
\hline 12 & Kım et al. [22] & 1999 & Korea & 58 & $\mathrm{~F}$ & X-ray/CT & Radiopaque & $3 \mathrm{~cm}$ & SB \\
\hline 13 & Tosato et al. [23] & 2000 & Italy & ND & M & Surgical & Radiolucent & ND & SB \\
\hline 14 & Vasquez et al. [24] & 2001 & USA & 60 & M & X-ray/CT & Radiolucent & $4 \mathrm{~cm}$ & MD \\
\hline 15 & Gamblin et al. [25] & 2003 & USA & 24 & $M$ & Surgical & Radiolucent & ND & SB \\
\hline 16 & Srinivas and Cullen [26] & 2007 & Belgium & 84 & $\mathrm{~F}$ & X-ray & Radiopaque & Multiple & MD \\
\hline 17 & Massoni Neto et al. [27] & 2007 & Brazil & 43 & $\mathrm{M}$ & X-ray & Radiopaque & Multiple & MD \\
\hline 18 & Tressallet et al. [28] & 2007 & France & 37 & $\mathrm{M}$ & CT & Radiopaque & ND & SB \\
\hline 19 & Rice et al. [29] & 2010 & USA & 73 & M & CT & Radiopaque & $3 \mathrm{~cm}$ & SB \\
\hline 20 & Lai [30] & 2010 & Taiwan & 9 & M & Surgical & Radiolucent & ND & Cecum \\
\hline 21 & Jones et al. [31] & 2010 & UK & 56 & M & X-ray/CT & Radiolucent & Multiple & MD \\
\hline 22 & Gadhia et al. [32] & 2010 & India & 55 & $M$ & X-ray/CT & Radiolucent & $6 \mathrm{~cm}$ & MD \\
\hline 23 & Garrigós et al. [33] & 2012 & Spain & 62 & $M$ & X-ray/Us & Radiopaque & $3 \mathrm{~cm}$ & SB \\
\hline 24 & Demetriou et al. [34] & 2013 & UK & 30 & $\mathrm{~F}$ & X-ray/CT & Radiopaque & $4 \mathrm{~cm}$ & SB \\
\hline 25 & Nguyen [35] & 2014 & Vietnam & 60 & $\mathrm{~F}$ & X-ray/CT & Radiolucent & $4 \mathrm{~cm}$ & SB \\
\hline 26 & Maurice et al. [36] & 2016 & Australia & 72 & M & X-ray/CT & Radiopaque & ND & SB and MD \\
\hline 27 & Dill et al. [37] & 2017 & Australia & 82 & M & X-ray/CT & Radiopaque & Multiple & MD \\
\hline 28 & Symeonidis et al. [10] & 2017 & Greece & 48 & $M$ & X-ray/CT & Radiopaque & $2.5 \mathrm{~cm}$ & SB \\
\hline 29 & Nastos et al. [38] & 2017 & Greece & 16 & $M$ & X-ray/MRI/CT & Radiopaque & $5 \mathrm{~cm}$ & MD \\
\hline 30 & Wauters et al. [39] & 2018 & Belgium & 42 & $M$ & X-ray/CT & Radiolucent & ND & SB \\
\hline
\end{tabular}

TABLE 1: Previous case reports from small bowel obstructions caused by Meckel's enterolith.

ND, no data; SB, small bowel; MD, Meckel's diverticulum; CT, computed tomography; MRI, magnetic resonance imaging

The pathogenesis of these enteroliths is unclear but there are several plausible hypotheses. One theory is that the absence of ectopic gastric mucosa preserves an alkaline environment which, when combined with stasis of succus entericus due to the absence of peristalsis by the diverticulum, promotes precipitation of calcium salts and stone formation. Additionally, previous episodes of MD with associated local inflammation may promote stone formation [40-41]. We hypothesize that MD enteroliths resulting in obstruction are rare because an MD must be large and broad-based to be capable of harboring and expelling a stone of sufficient caliber to cause luminal obstruction. It is unlikely that a single stone is retained long 
enough in a broad-based MD for it to grow to such a size.

Like most bowel obstructions associated with an intraluminal mass, the definitive treatment is operative intervention. As in the case presented, diverticulectomy including the enterolith is the preferred option. However, if the stone cannot be returned to the MD, bowel resection including the diverticulum with primary anastomosis is safe and effective. Segmental small bowel resection and anastomosis are also recommended for MD with a base greater than one-third of the bowel circumference, presence of inflammation, ulceration or perforation at the base, or suspected small bowel ischemia [42].

Regarding the approach, we anticipated difficulties with visualization due to small bowel dilatation from mechanical obstruction and thus decided to undertake a primary open exploration. Due to the anatomic location of MD, any obstruction secondary to MD enterolith would result in dilation of the vast majority of the small bowel. Therefore, laparoscopic resection may prove difficult and perilous but may be successful in selected patients.

\section{Conclusions}

In conclusion, despite $\mathrm{MD}$ is present in roughly $2 \%$ of the population and is usually asymptomatic, a wide variety of symptoms can develop at any age. All general surgeons will discover incidental MDs in their careers and resection of a normal-appearing diverticuli is not indicated but should be considered in the presence of observed or suspected pathology including enterolith. Moreover, when performing abdominal exploration to extract a mobile intraluminal body such as an enterolith, obstructing gallstone, or ingested object, an MD can serve as a useful vehicle for extraction while avoiding bowel anastomosis.

\section{Additional Information \\ Disclosures}

Human subjects: Consent was obtained or waived by all participants in this study. Conflicts of interest: In compliance with the ICMJE uniform disclosure form, all authors declare the following: Payment/services info: All authors have declared that no financial support was received from any organization for the submitted work. Financial relationships: All authors have declared that they have no financial relationships at present or within the previous three years with any organizations that might have an interest in the submitted work. Other relationships: All authors have declared that there are no other relationships or activities that could appear to have influenced the submitted work.

\section{References}

1. Huang CC, Lai MW, Hwang FM, et al.: Diverse presentations in pediatric Meckel's diverticulum: a review of 100 cases. Pediatr Neonatol. 2014, 55:369-375. 10.1016/j.pedneo.2013.12.005

2. Hansen CC, Søreide K: Systematic review of epidemiology, presentation, and management of Meckel's diverticulum in the 21st century. Medicine (Baltimore). 2018, 97:e12154. 10.1097/MD.0000000000012154

3. Christie A: Meckel's diverticulum: a pathologic study of sixty-three cases . Am J Dis Children. 1931, 42:544553. 10.1001/archpedi.1931.01940150043003

4. Sagar J, Kumar V, Shah DK: Meckel's diverticulum: a systematic review. J R Soc Med. 2006, 99:501-505.

5. Park JJ, Wolff BG, Tollefson MK, Walsh EE, Larson DR: Meckel diverticulum: the Mayo Clinic experience with 1476 patients (1950-2002). Ann Surg. 2005, 241:529-533. 10.1097/01.sla.0000154270.14308.5f

6. Lin XK, Huang XZ, Bao XZ, Zheng N, Xia QZ, Chen CD: Clinical characteristics of Meckel diverticulum in children: a retrospective review of a 15-year single-center experience. Medicine (Baltimore). 2017, 96:e7760. 10.1097/MD.0000000000007760

7. Blouhos K, Boulas KA, Tsalis K, et al.: Meckel's diverticulum in adults: surgical concerns . Front Surg. 2018, 5:55. 10.3389/fsurg.2018.00055

8. Yamaguchi M, Takeuchi S, Awazu S: Meckel's diverticulum: investigation of 600 patients in Japanese literature. Am J Surg. 1978, 136:247-249. 10.1016/0002-9610(78)90238-6

9. Papparella A, Nino F, Noviello C, Marte A, Parmeggiani P, Martino A, Cobellis G: Laparoscopic approach to Meckel's diverticulum. World J Gastroenterol. 2014, 20:8173-8178. 10.3748/wjg.v20.i25.8173

10. Symeonidis N, Kofinas A, Psarras K, Pavlidis E, Pavlidis T: Meckel's diverticulum enterolith: an extremely rare cause of intestinal obstruction. J Clin Diagn Res. 2017, 11:PD11-PD12. 10.7860/JCDR/2017/25941.9751

11. Field RJ Sr, Field RJ Jr: Intestinal obstruction produced by fecalith arising in Meckel's diverticulum . AMA Arch Surg. 1959, 79:8-9. 10.1001/archsurg.1959.04320070012002

12. Danzis M: Intestinal obstruction in Meckel's diverticulum with report of a case with a large enterolith . J Med Soc N J. 1950, 47:548-553.

13. Bergland RM, Gump F, Price JB Jr: An unusual complication of Meckel's diverticula seen in older patients . Ann Surg. 1963, 158:6-8. 10.1097/00000658-196307000-00002

14. Caridis DT, Smith G: [Occlusion of the small intestine by an enterolith from a Meckel's diverticulum] . Presse Med. 1965, 73:261-262.

15. Sbriccoli A: [Etiopathogenetic considerations on a case of ileus caused by enteroliths from Meckel's diverticulum]. Rass Int Clin Ter. 1969, 49:1459-1463.

16. Grosdidier J, Rollin B, Richaume B: [Intestinal obstruction caused by a coprolith originating in a Meckel's diverticulum]. Sem Hop. 1972, 48:2661-2664.

17. Benhamou G: Small intestinal obstruction by an enterolith from a Meckel's diverticulum . Int Surg. 1979, 64:43-45. 
18. Grant AB: Meckel stone ileus: a case report . Aust NZ J Surg. 1981, 51:77-78. 10.1111/j.14452197.1981.tb05912.x

19. Lopez PV, Welch JP: Enterolith intestinal obstruction owing to acquired and congenital diverticulosis. Report of two cases and review of the literature. Dis Colon Rectum. 1991, 34:941-944. 10.1007/BF02049713

20. Rudge FW: Meckel's stone ileus. Mil Med. 1992, 157:98-100.

21. McCallion WA, Higgins PM, Dane TE: Enterolith obstruction of the small bowel . Ulster Med J. 1992, 61:179181.

22. Kim YK, Kim YH, Lee YR, et al.: A case of Meckel's enterolith . Kor J Gastroenterol. 1999, 19:643-651.

23. Tosato F, Corsini F, Marano S, et al.: [Ileal occlusion caused by enterolith migrated from Meckel's diverticulum]. Ann Ital Chir. 2000, 71:393-396.

24. Vasquez JC, Lee SH, Coimbra R, Hoyt DB: Small bowel obstruction caused by a Meckel's diverticulum enterolith. Internet J Surg. 2001, 3:

25. Gamblin TC, Glenn J, Herring D, McKinney WB: Bowel obstruction caused by a Meckel's diverticulum enterolith: a case report and review of the literature. Curr Surg. 2003, 60:63-64. 10.1016/S01497944(02)00650-5

26. Srinivas GN, Cullen P: Intestinal obstruction due to meckel's diverticulum: a rare presentation . Acta Chir Belg. 2007, 107:64-66. 10.1080/00015458.2007.11680014

27. Massoni Neto LM, Hinkel BB, Doi A, Alcântara PSM de: Obstrução intestinal devido a enterolitos em divertículo de Meckel: relato de caso. Revista de Medicina. 2007, 86:155-162. 10.11606/issn.16799836.v86i3p155-162

28. Trésallet C, Renard-Penna R, Nguyen-Thanh Q, Cardot V, Chigot JP, Menegaux F: Intestinal obstruction by an enterolith from a perforated giant Meckel's diverticulum: diagnosis with CT reconstructed images. Int Surg. 2007, 92:125-127.

29. Rice RD, Parker DM, Seery JM, Arciero CA: A small bowel obstruction secondary to a Meckel's enterolith . Am Surg. 2010, 76:222-224.

30. Lai HC: Intestinal obstruction due to Meckel's enterolith . Pediatr Neonatol. 2010, 51:139-140. 10.1016/S1875-9572(10)60025-3

31. Jones KN, Glazebrook KN, Reynolds C: Pseudoangiomatous stromal hyperplasia: imaging findings with pathologic and clinical correlation. Am J Roentgenol. 2010, 195:1036-1042. 10.2214/AJR.09.3284

32. Gadhia U, Raju D, Kapoor R: Large enterolith in a Meckels diverticulum causing perforation and bowel obstruction: an interesting case with review of literature. Indian J Surg. 2013, 75:177-179. 10.1007/s12262012-0558-9

33. Garrigós G, Gómez SÁ, Peris N, Ripollés T, Martínez Abad M: [Intestinal obstruction due to Meckel's diverticulum enterolithiasis]. Cir Esp. 2012, 90:674-676. 10.1016/j.ciresp.2011.06.014

34. Demetriou V, McKean D, Briggs J, Moore N: Small bowel obstruction secondary to a liberated Meckel's enterolith. BMJ Case Rep. 2013, 2013: 10.1136/bcr-2013-008868

35. Nguyen T: Small bowel obstruction caused by Meckel diverticulum stones . (2015). Accessed: January 22, 2021: https://thuctapngoai2014.wordpress.com/2015/05/14/chuyen-de-tuan-3-tac-ruot-non-do-soi-tuithua-meckel-nguyen-trong-m....

36. Maurice AP, Dickfos M, Mousa P, Bhardwaj H, Godinho S, Iswariah H, Chandrasegaram M: Meckel's diverticulum enteroliths causing small bowel obstruction. ANZ J Surg. 2018, 88:E475-E476. 10.1111/ans.13423

37. Dill T, Sugo E, McManus B: Enteroliths and multiple neuroendocrine tumours in a Meckel's diverticulum . Pathology. 2017, 49:319-322. 10.1016/j.pathol.2016.10.016

38. Nastos C, Giannoulopoulos D, Georgopoulos I, et al.: Large enterolith complicating a Meckel diverticulum causing obstructive ileus in an adolescent male patient. Case Rep Surg. 2017, 2017:1871434. $10.1155 / 2017 / 1871434$

39. Wauters L, Peeters K, Van Hootegem A, Goetstouwers P, Delvaux P, Callens J: Meckel's enterolith: a rare cause of mechanical small bowel subobstruction. Acta Gastroenterol Belg. 2018, 81:534-537.

40. Gurvits GE, Lan G: Enterolithiasis. World J Gastroenterol. 2014, 20:17819-17829. 10.3748/wig.v20.i47.17819

41. Singhal BM, Kaval S, Kumar P, Singh CP: Enterolithiasis: an unusual cause of small intestinal obstruction . Arch Int Surg. 2013, 3:137. 10.4103/2278-9596.122936

42. Kuru S, Kismet K: Meckel's diverticulum: clinical features, diagnosis and management . Rev Esp Enferm Dig. 2018, 110:726-732. 10.17235/reed.2018.5628/2018 